\title{
Brazilian paralympic athletes: an evaluation of oral health status
} \author{
tina Núñez ${ }^{5}$ \\ 'Department of Oral Pathology, Health Institute of Nova Friburgo, Federal Fluminense University, Nova Friburgo, RJ, Brazil \\ ${ }^{2}$ Graduate student of Paulista University, São Paulo, SP, Brazil \\ ${ }^{3}$ Posgraduation program, Department of Oral Pathology, School of Dentistry, São Paulo University, São Paulo, SP, Brasil \\ ${ }^{4}$ Researcher of Institute of Health Research - INPES, São Paulo, SP, Brazil \\ ${ }^{5}$ Coordination of the Professional Master in Bioengineering. Brazil University, UNIVBRASIL, Itaquera, SP, Brazil \\ - Conflicts of interest: none declared.
}

Renata Tucci, ${ }^{1}$ Bruna Contador, ${ }^{2}$ Juliana Costa de Oliveira, ${ }^{3}$ Rafael Golghetto Domingos,${ }^{4}$ Alexandre Jun Zerbini Ueda, ${ }^{4}$ Hilton Sadayuki Tiba, ${ }^{4}$ Silvia Cris-

\section{Abstract}

Objective: To estimate the oral health status and investigate lifestyle habits that may reveal risk factors for dental caries of Brazilian competitive athletes and thus identify which oral health problems may impact their performance, enabling the implementation of public policies focused on this population. Material and Methods: This study collected data to describe the oral health status of Brazilian Paralympics Athletes participating in a government funded program named "Sports Dentistry for High Performed Athletes" performed at the Institute of Health Research - INPES in Sao Paulo, Brazil. A total of 96 high performed paralympic athletes were screened by 4 trained and calibrated dentists. Oral hygiene, reports of oral pain, TMJ examination, malocclusion index and sociodemographic information were recorded. Results: The age of the athletes ranged from 18 to 56 years, with a mean age of 34 years. The majority of the athletes were swimmers (55.2\%). $27.1 \%$ had gum bleeding, and $31.0 \%$ reported tooth sensitivity. $47.9 \%$ had class I (Angle) and most athletes (71.9\%) didn't show clinical signs of temporomandibular disorders. The mean of decayed, missing and filled index (DMFT) was 10.5, varying 0 to 28. Conclusions: clinical examinations indicate a population that significantly needs preventive and restorative oral health procedures. We hope that our data will be useful and assist the responsible authorities in creating curative and preventive public policies for the analyzed population. Keywords: Dentistry; Athletes; Epidemiology; Dental health survey; Sports; Athletic performance

\section{Introduction}

$\mathrm{D}$ entistry applied to sports focuses on the study, revision, prevention and treatment of orofacial traumatology, on athlete dental health maintenance, and on the diffusion of information and new knowledge within the sports medicine community.,

Sports dentistry is far more than just the provision of mouthguards and should include the diagnosis of dental disease and pathologies that could impact upon the athlete. ${ }^{3}$ Poor dental health can limit an athlete's ability to train and compete at their very best and acute dental conditions such as pulpal, periodontal and mucosal inflammation and, in particular, pericoronitis regularly can and do force athletes either to withdraw from a competition or perform at a reduced level. ${ }^{4,5}$

The high-performance standards required of athletes can only be attained by a totally healthy individual. The time, effort and money invested in achieving this maximum level of fitness should not be put at risk by preventable general and oral health problems occurring prior to, or during competition. ${ }^{6,7}$

The dentist is able to offer to athletes improvement in their physical performance through the maintenance of oral health, preventing and treating any and all changes in the stomatognathic system that compromise the athlete's performance. $^{8}$
Vougiouklakis et. al., 2008 emphasizes the importance of a dental team in major events. During the Athena's Paralympics Games, the authors found more than 240 dental cases in more than 220 patients. Among them 73 fillings were made, 12 root canal treatments, 21 teeth extractions and 3 dental trauma cases were treated. ${ }^{9}$ Similarly, Gallaguer et. al., 2016 provided strong evidence of the prevalence of oral health diseases and associated performance impacts in in a representative sample of UK elite athletes. In such events, highly trained dentists are needed and if possible, specialized in operative dentistry or endodontics. Therefore, the role of dentist' team can be assumed as of great importance. ${ }^{10}$

According to a paper published by the International Olympic Committee, 2009, the oral health evaluation has significant relevance to the establishment of an improvement in oral health. Good oral health will ensure good function and the ability of the athlete to compete at an optimal level without being compromised by dental disease or an otherwise preventable emergency. ${ }^{11}$

Although in recent years there has been an increasing interest in the oral health of elite and amateur athletes the research in this field is limited. ${ }^{12}$ In the worldwide are few epidemiological studies on the oral health status of paralympics athletes, and findings about the oral health status of Brazilian athletes are unprecedented. 
Whereas the improvement of preventive sports dentistry depends on the epidemiological research, this study aimed to estimate the oral health status and to investigate lifestyle habits that could reveal risk factors for dental caries of Brazilian competitive athletes, and thus identify what oral health issues they might experience that would impact on performance.

\section{Material and Methods}

This study was a retrospective review of an oral data collected from parathletes participating in a government funded program named "Sports Dentistry for High Performed Athletes" performed at the Institute of Health Research INPES in Sao Paulo, Brazil between the years 2011 and 2012.

Ethical approval was gained from the Human Ethics Committee of Biomedical Science Institute - University of Sao Paulo. All participating athletes received funding from the Ministry of Sports of the Brazilian Federal Government. All athletes who have had dental problems detected during the evaluation were referred for treatment in our own institute - INPES, with the support of Procter and Gamble/ OralB.

A standardized screening protocol was developed for assessing the oral health status of Brazilian parathletes. The participants were classified according to age, sex and sports modalities. Four dentists, who had been trained and calibrated recorded noninvasive oral examinations conducted with artificial light using diagnostic dental equipment. Reviewed oral hygiene, gingival status, dental caries and missing teeth were evaluated.

The examined athletes were questioned regarding a series of basic sociodemographic items. The decayed, missing and filled index (DMFT), Angle molar class, parafunctional habits, palpation of masticatory muscles and presence of temporomandibular disorders symptoms were also evaluated.

All data collected were entered into a software application for compilation and descriptive statistical analysis.

\section{Results}

Among the 96 participants athletes with physical challenges the nature of the impairments were: physical and motor disabilities (53); Down syndrome (22); visual disabilities (16); cerebral palsy (4) and Fetal alcohol syndrome (1). The majority of the athletes were swimmers $(26-27.08 \%)$ and participants of athletics modalities (23 - 23.95\%) (Figure 1).

When separated by sports modalities, we found that the 37 parathletes with motor and physical disabilities practice a wider variety of sports. Parathletes with Down syndrome practice more swimming, whereas most visually impaired participants practice athletics (Table 1).

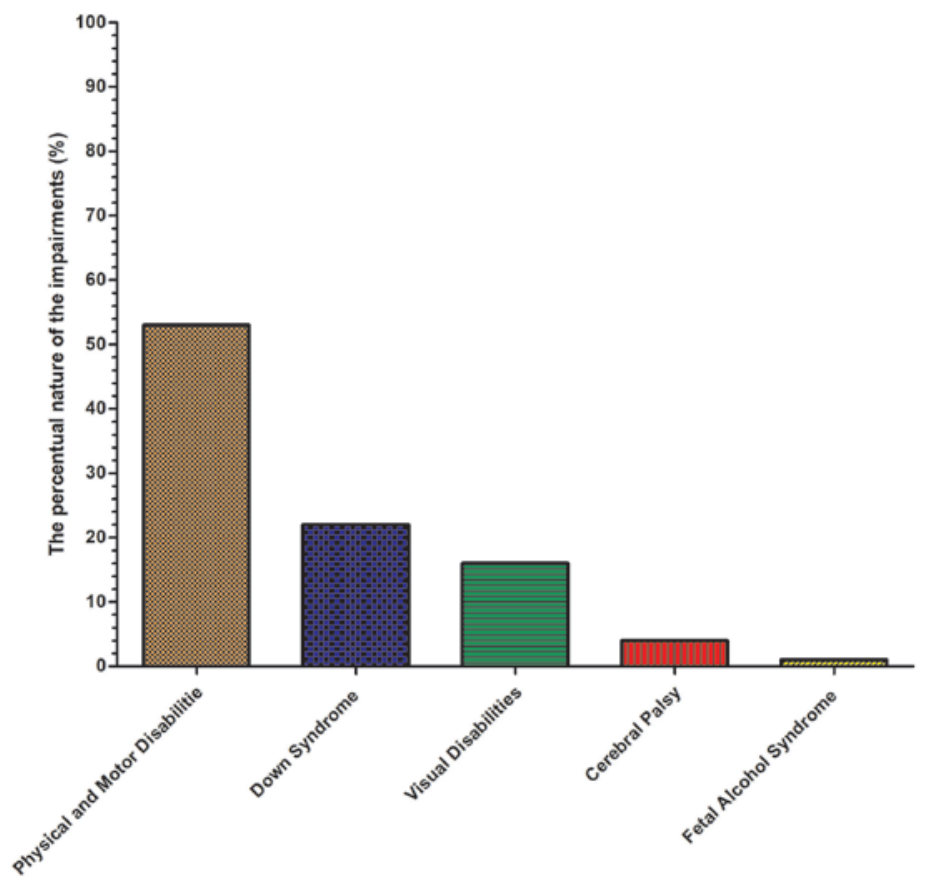

Figure 1. Brazilian paralympic athletes: Distribution in absolute numbers according to sports practiced

The age of the participants ranged from 18 to 56 years, with a mean age of 34 years. Gender distribution was 67 males (69.7\%) and 29 females (30.3\%). Sixty-one players (63.5\%) were regularly seen by dentists and had undergone a check-up during the last year, thought 19 (19.9\%) claimed that they just went to the dentist when feel pain. Eightyeight $(91.6 \%)$ said that they brushed their teeth two or more times a day. However, only 47 parathletes (48.9\%) used dental floss one or more times a day and 49 (51.1\%) never used. Forty-one (42.7\%) said that they use some type of mouth rinse. Decayed, missing and filled index (DMFT) average was 10.5 , varying from 0 to 28 . Fourteen parathletes had $\mathrm{DMFT}=0$ and twelve parathletes had DMFT over 20. The highest mean DMFT was found in the age group of 51 to 55 years, with a mean value of 18.3 . (Table 2 ). Of the 96 disabled athletes, 19 use some type of dental prosthesis (19.8\%).

Thirty parathletes (31.2\%) reported frequent experiences of tooth sensitivity, while 26 (27.1\%) reported gum bleeding. Regarding harmful habits, most parathletes presented onychophagy (23 - 23.9\%), followed by bruxism (13 - 13.5\%).

When we assessed the dietary habits, sixty-one parathletes $(63.5 \%)$ reported eating between meals, sixty-two (64.6\%) claim to eat sweets often; sixty-nine (71.8\%) drink refrigerants and thirty one make use of a dietary supplement based on carbohydrate and protein.

The temporomandibular joint (TMJ) screening survey showed that only 6 athletes reported experiencing tinnitus and pain during mouth opening, while 16 had midline deviation. Palpation on the TMJ caused pain in 1 parathlete. 46 participants $(47.91 \%)$ had class I (An- 
gle) occlusion, 28 (29.16\%) had class II occlusion and 14 had no molars and thus their occlusion was not evalu(14.58\%) had class III occlusion. Eight athletes $(8.33 \%)$ ated.

Table 1. Overall oral health findings of high performance Brazilian athletes. ( $n=200$; mean age, 25,59 years).

\begin{tabular}{|c|c|c|}
\hline Parameters & $\mathbf{n}$ & $\%$ \\
\hline \multicolumn{3}{|l|}{ Gender } \\
\hline Male & 105 & 52.5 \\
\hline Female & 95 & 47.5 \\
\hline \multicolumn{3}{|l|}{ When was your last visit to the dentist? } \\
\hline Last year & 117 & 58.5 \\
\hline More than one year ago & 83 & 41.5 \\
\hline \multicolumn{3}{|l|}{ Brushing frequency } \\
\hline One time/day & 4 & 2 \\
\hline Two to three times/day & 146 & 73 \\
\hline Four to six times/day & 43 & 21.5 \\
\hline $\mathrm{n} / \mathrm{a}$ & 7 & 3.5 \\
\hline \multicolumn{3}{|l|}{ How often do you use dental floss? } \\
\hline One or more times/day & 119 & 59.5 \\
\hline Never & 81 & 40.5 \\
\hline \multicolumn{3}{|l|}{ Harmful habits } \\
\hline Bruxism & 28 & 14 \\
\hline Onychophagia & 37 & 18.5 \\
\hline Teeth clenching & 14 & 7 \\
\hline
\end{tabular}

Angle' classification

Class I

Class II

Class III

$\mathrm{n} / \mathrm{a}$

Facial asymmetry

Tinnitus

Pain opening the mouth

Midline deviation

Use of dental prosthesis

\section{Oral Hygiene}

\section{Good}

Moderate

Poor

Dental sensibility

Gum bleeding

Dental erosion

Dental abfraction

Alterations of oral mucosa

Ingestion of sweets

Drink soda

Eating between meals

Received instructions about the importance of oral health for the athlete's performance? n/a $=$ not available 
Finally, sixty-one parathletes reported that they never received information about the importance of oral health on athletes' performance, while 35 (36.4\%) said they had received advice from their dentists. The data is summarized in Table 3.

Table 2. Average value DMFT obtained in Brazilian Paralympics Athletes

\begin{tabular}{l|c|c}
\hline $\begin{array}{c}\text { AGE GROUP } \\
\text { (years) }\end{array}$ & $\begin{array}{c}\text { DMFT } \\
\text { Average of } \\
\text { Parathletes }\end{array}$ & $\begin{array}{c}\text { TOTAL } \\
\text { Number of Athletes } \\
\text { in this Age Group }\end{array}$ \\
\hline 15 to 20 & 0 & 4 \\
\hline 21 to 25 & 3.7 & 14 \\
\hline 26 to 30 & 4.5 & 20 \\
\hline 31 to 35 & 8.1 & 20 \\
\hline 36 to 40 & 10.7 & 13 \\
\hline 41 to 45 & 18.0 & 12 \\
\hline 46 to 50 & 17.4 & 9 \\
\hline 51 to 55 & 18.3 & 1 \\
\hline 55 to 60 & 11 & \\
\hline
\end{tabular}

DMFT $=$ Decayed, Missing, Filled Teeth

\section{Discussion}

To the best of our knowledge this is the first report on the oral health status of Brazilian Paralympic Athletes and thus our findings can be compared with few papers in the literature. Most of the reports are part of the program "Special Olympics Special Smiles", which promotes noninvasive oral health screening and referrals, data collection, oral health education, and preventive dentistry for athletes competing in sports activities throughout the world. The reports often deal with different age groups and they differ on the analyzed parameters. ${ }^{13,14,15,16,17,18}$

The comparison of data collect from the paralympic athletes with the data obtained from the general population may be imprecise due to differences in data collection and sample selection methods. ${ }^{19,20}$

Our results showed that most athletes brush their teeth two to three times a day (73.9\%), as evidenced by the good oral hygiene observed in $62 \%$ of cases after clinical evaluation, as well as the low index of bleeding on probing (27.1\%). As in our study, Fernandez et al., 2012 also found signs of gum disease in $32 \%$ of the special athletes evaluated by them in New York. ${ }^{19}$

Although most athletes reporting visit their dentist once a year (63.5\%), only $36.4 \%$ reported that they had received instructions about the importance of oral health for athletics' performance. This data shows the need for greater involvement of the dental team on the integral preparation of high-performance athlete, considering that there are numerous dental problems that can interfere with their systemic health, and consequently on their performance.
Table 3. Overall oral health findings of the Paralympics Athletes examined. ( $n=96$; mean age, 34 years).

\begin{tabular}{|c|c|c|}
\hline Parameters & $\mathbf{n}$ & $\%$ \\
\hline \multicolumn{3}{|l|}{ Gender } \\
\hline Male & 67 & 69.7 \\
\hline Female & 29 & 30.3 \\
\hline \multicolumn{3}{|l|}{ When was your last visit to the dentist? } \\
\hline Last year & 61 & 63.5 \\
\hline More than five years ago & 16 & 16.6 \\
\hline Just go to the dentist when I feel pain & 19 & 19.9 \\
\hline \multicolumn{3}{|l|}{ Brushing frequency } \\
\hline One time/day & 1 & 1.1 \\
\hline Two to three times/day & 71 & 73.9 \\
\hline Four to six times/day & 17 & 17.7 \\
\hline $\mathrm{n} / \mathrm{a}$ & 7 & 7.3 \\
\hline \multicolumn{3}{|l|}{ How often do you use dental floss? } \\
\hline One or more times/day & 47 & 48.9 \\
\hline Never & 49 & 51.1 \\
\hline \multicolumn{3}{|l|}{ Harmful habits } \\
\hline Bruxism & 13 & 13.5 \\
\hline Onychophagia & 23 & 23.9 \\
\hline Teeth clenching & 6 & 6.2 \\
\hline \multicolumn{3}{|l|}{ Angle' classification } \\
\hline Class I & 46 & 47.9 \\
\hline Class II & 28 & 29.1 \\
\hline Class III & 14 & 14.6 \\
\hline $\mathrm{n} / \mathrm{a}$ & 8 & 8.3 \\
\hline Facial asymmetry & 37 & 38.5 \\
\hline Tinnitus & 6 & 6.2 \\
\hline Pain opening the mouth & 6 & 6.2 \\
\hline Midline deviation & 39 & 40.6 \\
\hline TMJ pain on palpation & 1 & 1.1 \\
\hline Use of dental prosthesis & 19 & 19,8 \\
\hline \multicolumn{3}{|l|}{ Oral Hygiene } \\
\hline Good & 60 & 62.5 \\
\hline Moderate & 24 & 25 \\
\hline Poor & 12 & 12.5 \\
\hline mouthwash use & 41 & 42.7 \\
\hline Ingestion of candies & 62 & 64.6 \\
\hline Eating between meals & 61 & 63.5 \\
\hline Ingestion of refrigerants & 69 & 71.8 \\
\hline $\begin{array}{l}\text { Use of a dietary supplement (carbohydrate and } \\
\text { protein) }\end{array}$ & 31 & 32.3 \\
\hline Dental sensibility & 30 & 31.2 \\
\hline Gum bleeding & 26 & 27.1 \\
\hline $\begin{array}{l}\text { Received instructions about the importance of oral } \\
\text { health for the athlete's performance? }\end{array}$ & 35 & 36.4 \\
\hline
\end{tabular}

$\mathrm{n} / \mathrm{a}=$ not available 
Despite the quality of oral hygiene an interesting factor to note is the amount of athletes who claimed never flossing (51.1\%). The no flossing behavior added to other habits as high intake of sweets, eating between meals and high intake of sodas put this group of patients at high risk for dental caries development. Therefore, we can conclude that the DMFT index that we reported is directly linked with the abovementioned factors. Athletes between 41 to 55 years had a higher DMFT than the younger group. The lower DMFT in younger patients is important because it shows a trend towards better oral care for patients with any type of disability. It is also noteworthy the high DMFT in patients with visual impairments denoting the need for constant monitoring among these patients in terms of oral hygiene quality. On the other hand, patients with Down syndrome showed a DMFT index and oral condition very similar to that expected for patients without disability. The Down syndrome caregivers were very participative, and their participation seems to be directly linked with the quality of oral health.

Dental caries and periodontal disease are the two most prevalent oral diseases and may compromise eating, speech and self-esteem. In addition, evidence has demonstrated that poor oral health is associated with malnutrition, weight loss, systemic diseases and focal infections. ${ }^{18}$ The situation that we recorded was different from that observed by Oredugba et al., 2010, ${ }^{17}$ and by a Romanian study, ${ }^{21}$ that reported a poor index of dental care. According to Oredugba et al., 2010 the main reason for their findings was the lack of care or knowledge by the caregivers. ${ }^{17}$

In general, the DMFT of athletes with disabilities was very close to that found in the Brazilian population. In the last oral health survey held in BRAZIL, 2010, the researchers expected a mean DMF of 16.3 for individuals between 35-44 years old. Our study calculated a mean of 10.7 for individuals between 36 and 40 years old, therefore smaller than we expected, and an average of 18.1 for patients between 41 and 45 years old. ${ }^{22}$

In regards to Angle's molar relationship 47.9\% are in Class I, 29.1\% are in Class II and $14.6 \%$ are in Class III. These data are different from those reported by Souza et al., 2011 evaluating soccer player where the authors found $89 \%$ of athletes with class I. Among the non-athletes population, Ferreira et al., 2010 showed that the Class I malocclusion was the most frequent (82.9\%), followed by Class II (12.1\%) and Class III $(5 \%),{ }^{23}$ thus the values are near to the ones observed by Souza et al., 2011. ${ }^{8}$

In clinical practice we can observe that many patients with malocclusion have some harmful oral habits which may act as main or supporting causes that affect the shape and / or function of the stomatognathic system, such as digestive problems and non-absorption of nutrients necessary to attain their highest degree of performance. Antonini et al,
2005 observed that sucking habits seem to be related to the skeletal maxillary protrusion and Class II skeletal pattern. In our study the most frequent deleterious habit reported was nail biting (23.9\%), followed by $13.5 \%$ of bruxism. Sucking habits such as sucking fingers and pacifiers were only reported by 4 athletes (4.2\%). ${ }^{24}$ As our findings regarding class II incidence were slightly higher than the data reported in the literature, more studies with Paralympics athletes are required to confront with our findings. These can interfere with perfect occlusion, respiration, swallowing, and digestion, in addition to contributing to the occurrence of dental trauma. Many studies support the theory that dental occlusion affects posture, muscular strength and output, that induces a chain of adverse reactions, resulting in postural modification and compensation by the locomotor system. This creates mechanical constraints and imbalances, and these biomechanical consequences result in unequal force distribution in the body's lower extremity, the feet, and also affect the symmetry of movement and human dynamics. ${ }^{25}$

Another interesting data is the high rate of midline shift (40.6\%) observed which may be linked with alterations in the skeletal structural and with orthodontic/occlusal problems as crossbite, discrepancy in teeth size, absence of arcade components, spacing, crowding and occlusal landslides In addition to the disorders described so far, postural problems may be occur in the athletes having this type of malocclusion. ${ }^{3,18}$ The examined athletes also showed 38.5\% of facial asymmetry, a fact in agreement with the literature, which shows a prevalence rate of $21 \%$ to $85 \%$ of facial asymmetry. We agree with Vasconcelos et al., 2012, that stated that the variation on these percentages may be affected by several factors as sample characteristics, type of dentofacial deformity and evaluation methodology. ${ }^{26}$

In summary, this study presents important data to estimate the oral health condition in Brazilian parathletes, since it is possible to detect the factors that influence the prevalences found. Our results show the evident need for attention for this population, which despite presenting indicators similar to the general population, is definitely more vulnerable. In addition, our pioneering study in this observation highlights the lack of information on the impact of the factors analyzed here on athletes' performance.

\section{Conclusion}

Although an initial evaluation, the results of clinical examinations indicate a population that significantly needs preventive and restorative oral health procedures, as well as guidance on the harmful habits observed. We hope that our data will be useful and assist the responsible authorities in creating curative and preventive public policies for the analyzed population. 


\section{Acknowledgement}

The authors are grateful to Ministério do Esporte - Brazil - Secretaria de Alto Rendimento, by funding the project through the covenant with INPES / ME in $732398 / 2010$.
Procter and Gamble/Oral B who sponsored INPES and enables the dental treatment of the Brazilian athletes and parathletes

The authors are thankful to Brazilian athletes who participated in the evaluation enabling the research.

\section{References}

1. Gay-Escoda C, Vieira-Duarte-Pereira DM, Ardèvol J, Pruna R, Fernandez J, Valmaseda-Castellón E. Study of the effect of oral health on physical condition of professional soccer players of the Football Club Barcelona. Med Oral Patol Oral Cir Bucal. 2011;16(3): e436-9.

2. Soares PV, Tolentino AB, Machado AC, Dias RB, Coto N.P. Sports Dentistry: a perspective for the future. Revista Brasileira de Educação Física e Esporte, 2014;28(2):351-358.

3. Chapman P, Nasser B. Prevalence of orofacial injuries and use of mouthguards in high school Rugby Union. Aust Dent J. 1996; 41: 252-5.

4. Newsome P, Owen S, Reaney D. The dentist's role in the prevention of sports-related oro-facial injuries. Int Dent AS. 2010; 12(1):50-60.

5. Needleman I, Ashley P, Fine P, Haddad F, Loosemore, M, de Medici, A, et. al. Oral health and elite sport performance. Br J Sports Med, 2015; 49(1): 3-6.

6.Soler Badia D, Batchelor PA, Sheiham A. The prevalence of oral health problems in participants of the 1992 Olympic Games in Barcelona. Int Dent J. 1994;44:44-8

7. Dagon N, Blumer S, Peretz B, Ratson T. Prevalence of dental trauma in individuals with special needs participating in local Special Olympics games. Special Care in Dentistry, 2019;39(1): 34-38.

8. Souza LA, Elmadjian TR, Brito e Dias R, Coto NP. Prevalence of malocclusions in the 13-20-year-old categories of football athletes. Braz Oral Res 2011;25(1):19-22.

9. Vougiouklakis G, Tzoutzas J, Farmakis ET, Farmakis EE, Antoniadou M, Mitsea A. Dental data of the Athens 2004 Olympic and Paralympic Games. Int J Sports Med. 2008;29(11):927-33.

10. Gallagher J, Ashley P, Petrie A, Needleman I. Oral health and performance impacts in elite and professional athletes. Community dentistry and oral epidemiology, 2018;46(6): 563-568.

11. International Olympic Committee. The International Olympic Committee (IOC) Consensus Statement on Periodic Health Evaluation of Elite Athletes. J Athl Train. 2009;44(5): 538-557.

12. Frese C, Wohlrab T, Sheng L, Kieser M., Krisam, J., Frese, F., \& Wolff, D. Clinical management and prevention of dental caries in athletes: A four-year randomized controlled clinical trial. Scientific reports. 2018;8(1), 16991.

13. Feldman CA, Giniger M, Sanders M, Saporito R, Zohn HK, Perlman SP. Special Olympics, special smiles: assessing the feasibility of epidemiologic data collection. J Am Dent Assoc. 1997; 128:1687-96.
14. Perlman S. Helping Special Olympics athletes sport good smiles. An effort to reach out to people with special needs. Dent Clin North Am. 2000; 44:221-9.

15. López del Valle LM, Waldman B, Perlman SP. Puerto Rican Athletes With Special Health Care Needs: An Evaluation of Oral Health Status. J Dent Child (Chic). 2007;74(2):130-2.

16. Turner S, Sweeney M, Kennedy C, Macpherson L. The oral health of people with intellectual disability participating in the UK Special Olympics. J Intellect Disabil Res. 2008;52(Pt 1):29-36.

17. Oredugba FA, Perlman SP. Oral health condition and treatment needs of Special Olympics athletes in Nigeria. Spec Care Dentist. 2010;30(5):211-7.

18. Marks L, Wong A, Perlman S, Shellard A, Fernandez C. Global oral health status of athletes with intellectual disabilities. Clinical oral investigations, 2018; 22(4), 1681-1688.

19. Fernandez JB, Lim LJ, Dougherty N, LaSasso J, Atar M, Daronch M. Oral health findings in athletes with intellectual disabilities at the NYC Special Olympics. Spec Care Dentist. 2012;32(5):205-9.

20. Navarro FAA, Silva Guimarães L, Azeredo LAA, Santos Antunes L. Global prevalence of dental caries in athletes with intellectual disabilities: An epidemiological systematic review and meta-analysis. Special Care in Dentistry, 2019;39(2), 114-124.

21. Roman A, Tigan S, Pastrav D. Caries among a group of Romanian intellectually impaired children. J Dis Oral Health. 2004:5:80-2.

22. ________Brasil. Ministério da Saúde. Secretaria de Atenção à Saúde. Saúde Bucal 2010 - Pesquisa Nacional de Saúde Bucal: resultados principais [internet]. Brasília: Editora do Ministério da Saúde, 2012. 118 p.

23. Ferreira JTL, Lima MRF, Pizzolato LZ. Relação da má oclusâo de Classe II de Angle com hábitos bucais deletérios. Dental Press J Orthod. 2012; 17C6:111-7. 24. Antonini A, Marinelli A, Baroni G, Franchi L, Defraia E. Class II malocclusion with maxillary protrusion from the deciduous through the mixed dentition: a longitudinal study. Angle Orthod. 2005;75(6):980-6.

25. Budd SC, Egea JC. Dental Occlusion and Athletic Performance. In: Sport and Oral Health. Springer, Cham, p.91-98. 2017

26. Vasconcelos BCE, Gonçalves F, Andrade A, Guillen M, Landim F. Mandibular asymmetry: literature review and case report. Braz J Otorhinolaryngol. $2012 ; 78(4): 137$

\section{Mini Curriculum and Author's Contribution}

1. Renata Tucci, DDS, PhD Contribution: project's supervision, writing of the manuscript and reviewing of references. ORCID: 0000-0003-2295-6305

2. Bruna Contador, Graduate dentist. Contribution: data collection and writing of the manuscript. ORCID: 0000-0002-8634-4642

3. Juliana Costa de Oliveira, Graduate dentist, Contribution: critical review of the manuscript and reviewing of references. ORCID: 0000-0002-8741-7743

4. Rafael Golghetto Domingos, Graduate dentist. Contribution: data collection and writing of the manuscript. ORCID: 0000-0002-8746-7265

5. Alexandre Jun Zerbini Ueda, DDS. Contribution: data collection and writing of the manuscript. ORCID: 0000-0002-6130-3924

6. Hilton Sadayuki Tiba, DDS. Contribution: analysis and interpretation of the data and writing of the manuscript. ORCID: 0000-0002-2045-5278

7. Silvia Cristina Núñez, DDS, PhD. Contribuition: conception and design of the study project's supervision. ORCID: 0000-0003-2101-8333 